Revista Complutense de Educación

ISSNe: 1988-2793

http://dx.doi.org/10.5209/RCED.60084

\title{
Y la arqueología llegó al aula. La cultura material y el método arqueológico para la enseñanza de la historia y el patrimonio
}

Autores: Alejandro Egea Vivancos, Laura Arias Ferrer y Joan Santacana i Mestre (coords.)

Editorial: Ed. Trea (Gijón)

Año de publicación: 2018

$N^{\circ}$ de páginas: 343

ISBN: 978-84-17140-18-2

Los coordinadores de esta monografía han tenido a bien organizar este volumen que recoge distintos trabajos donde la arqueología aparece como un puente proyectado para conseguir una serie de objetivos didácticos que culminen con la educación del alumnado dentro de la base de una educación democrática e integradora. De ahí la importante contribución que supone este libro para la comunidad científica asociada al mundo universitario pero, también, al ámbito de la educación Infantil, Primaria y Secundaria.

De este modo, Alejandro Egea (Universidad de Murcia), Laura Arias (Universidad de Murcia) y Joan Santacana i Maestre (Universidad de Barcelona), nos proponen un interesante viaje para ponderar la importancia que esta disciplina posee actualmente y que puede tener en un futuro próximo en la enseñanza.

La primera aportación, corresponde a uno de los coordinadores de esta obra: Joan Santacana. En este primer capítulo se nos hace partícipes de una idea nuclear: la arqueología es una herramienta de vital importancia para la educación por su inminente carácter multidisciplinar. Además, elabora un manifiesto sobre la utilidad que tiene que la arqueología no esté aislada de la sociedad, de ahí la importancia de llevarla a las aulas para dotar de más fuerza la educación en valores de los estudiante.

Tras esta importante aportación, en el primer bloque temático encontramos un capítulo dedicado al lugar que ocupa actualmente la arqueología en la educación española (pp. 25-44). De esta forma, Antonio J. Meseguer, Estefanía Caballero, Laura Arias y Alejandro Egea nos muestran cómo, a pesar de la potencialidad de la metodología arqueológica en el proceso de enseñanza/aprendizaje, actualmente en España apenas se desarrollan sus posibilidades ya que, en términos generales, la educación de la historia aún está anclada en el pasado didáctico, siendo una asignatura esencialmente conceptual y descriptiva de condición memorística donde no se desarrolla un pensamiento histórico que permita a los alumnos adquirir conocimientos útiles.

El segundo bloque temático es relativo a las intervenciones arqueológicas en yacimientos reales (como el de la Tira del Lienzo en Totana) o en yacimientos simulados (como el realizado en Lorca). En este sentido, se nos presentan diferentes ejemplos en los capítulos de M. Jay Stottman (pp. 47-70), de Bev Forrest y Dave Weldrake (pp. 71-86), de José Antonio González Guerao (pp. 87-98) y de Miguel Pallarés, Antonio Carrión y Noelia Sánchez (pp. 99-118). En ellos se reflexiona sobre la importancia que tiene el hecho de realizar una excavación arqueológica con alumnado, 
no solo para aportar conocimientos significativos en el ámbito del pensamiento histórico e, incluso, en el arqueológico, sino también en otras materias al poder realizar con esta metodología de una excavación arqueológica un proyecto interdisciplinar e interdepartamental en un instituto. Por supuesto que para poder realizar esto, se necesita un concienzudo estudio de planificación y una organización rigurosa.

El siguiente bloque temático está basado en aspectos de la didáctica del objeto. De este modo, nos encontramos con las contribuciones de Laura Arias y Elizabet Casanova con alumnos de 4 años (pp. 121-135), donde se realiza un aprendizaje basado en proyectos para poder promover un aprendizaje significativo y activo a través de una serie de estrategias didácticas con un objeto arqueológico y de M. ${ }^{a}$ Josefa Morales y Alejandro Egea con alumnos de 8-9 años (pp. 137-157). En esta segunda aportación se elabora, a través del proyecto "Un día en la vida de Lucio Numisio", una metodología didáctica destinada a fomentar el número de aspectos hipotéticodeductivos, logrando así que mejore la capacidad de análisis del alumnado. En esta línea también se orientan las aportaciones de la investigadora portuguesa Helena Pinto sobre las estrategias didácticas que posee el estudio con objetos romanos en el alumnado (pp. 159-180), de la profesora norteamericana Linda S. Levstik (pp. 181-194) que proporciona una unidad complementaria de currículo de ciencias y estudios sociales para ayudar a la adquisición de conocimientos del alumnado y de M. ${ }^{\mathrm{a}}$ Luisa López Gómez (pp. 195-216), que también incurre en aspectos museográficos al elaborar junto con sus alumnos una especie de museo con las replicas estudiadas, elaboradas y analizadas en clase. Las otras aportaciones de este bloque temático son las propuestas por Tània Martínez Gil, Victoria López Benito y Joan Santacana I Mestre (pp. 217-230) donde, como ellos mismos reconocen, la arqueología ofrece un poderoso medio para enseñar el método y análisis científico a través de lo que denominaron como "LabCase o Kits didácticos". Otra interesante aportación es la realizada por Francisco Ramos, Juan Gallardo y Ana Irigoyen (pp. 231-249) donde analizan distintas tecnologías de nuevo cuño, relacionadas con la arqueología, que podrían tener una gran potencialidad para la enseñanza. De este modo, los autores de esta contribución ponen en valor el interés que tendría incorporar al aula los códigos QPR, las aplicaciones de móviles, los dispositivos de realidad virtual, etc.

El último gran bloque temático se vincula de manera estrecha con los dos anteriores, puesto que pertenecen a campos arqueológicos cuya auténtica función es el aprendizaje, pero un aprendizaje que parte de enseñar desde la arqueología. Las contribuciones de este bloque temático pertenecen al equipo norteamericano encabezado por A. Gwynn Henderson (pp. 253-290) y de Antonio Bardavio y Sònia Mañé (pp. 291-326).

El libro finaliza con unas conclusiones donde se traza un panorama esperanzador para la inclusión de esta metodología en las aulas y sus posibilidades para el desarrollo del denominado pensamiento histórico.

A modo de conclusión, el éxito del que parte este libro es el de aglutinar las principales visiones y propuestas que sobre este tema se vienen realizando a nivel nacional e internacional, integrando una puesta en común de los avances e interrogantes de estos proyectos para su puesta en práctica y mejora. Desde esta perspectiva, este libro pudiera sentar las bases y crear todo un marco de influencia en futuros proyectos de esta naturaleza.

José Ángel Castillo lozano

Universidad de Murcia joseangel.castillo1@um.es 